\title{
Health Risks and Safety Assessments of the Bathrooms for the Elderly in Phatthalung Province, Southern Thailand
}

\author{
Thitima na Songkhla ${ }^{1 *}$, Somsiri Decharat ${ }^{1}$ and Sutee Inraksa ${ }^{1}$ \\ ${ }^{I}$ Department of Occupational Health and Safety, Faculty of Health and Sports Science, Thaksin University \\ *Corresponding author. Email: nthitima@tsu.ac.th
}

\begin{abstract}
The number of elderly people in Thailand has been increasing continuously. Using the toilets is a daily necessity for them. The aim of this study is to assess the elderly's toilets on health risks and safety. There were 278 respondents in this study which was carried out as an exploratory and descriptive study by investigating 278 bathrooms in Pa Phayom Sub-District, Phatthalung Province, Southern Thailand. The result revealed the risk hazard areas in the house for the elderly were bathrooms (202 respondents or $72.66 \%$ ). The elderlies have experienced an accident in the bathrooms (42 respondents or $15.11 \%$ ). Besides, the overall bathroom safety of elderly was acceptable. There were some items whose levels were unacceptable and poor such as insufficient toilet paper to use, no shower seat/chair, no backrest for the elderly who cannot sit on their own, no flush toilet, no handrails on the wall for support, no signal or alarm/call for helpers and narrow door. Hence, the government or health authority needs to educate the elderly or helpers to be more aware of health risks and safety measures of using the bathrooms among the elderly, to promote using the bathrooms which are safe or appropriate for their health and to support some facilities which help them to improve their bathrooms including specific emergency equipment in the toilet. These measures will assist in reducing the negative health effects and increasing safety among the elderly.
\end{abstract}

Keywords: Health Risk, Safety, Assessment, Bathroom, Elderly

\section{INTRODUCTION}

The ageing population is increasing rapidly in Thailand, which is the case in many other countries as well. The statistics of the elderly in Thailand from 2018 to 2020 are $16.06 \%, 16.73 \%$ and $17.57 \%$ respectively. It can be seen that the trend is increasing every year. Moreover, the statistics of the elderly in 2020 of $\mathrm{Pa}$ Phayom sub-district are $17.38 \%$, which is comparable to the national level [1]. The study of accident statistics of the elderly showed that $31 \%$ were slip, fall and collapse in the bathrooms [2]. The bathrooms are considered as important household areas because they are the rooms with humidity where there are wet parts that are prone to accidents. The bathrooms are risky areas to have most accidents from slipping inside which can occur so often that these accidents can be fatal. The elderly gradually slow down due to the decline of their own body functions. Therefore, the need for their safety is more serious [3]. The bathroom safety considerations for the elderly should include the floor, shower enclosure, space for dressing, drying, undressing, removing or replacing clothes, chairs to sit on, hand grips to hold onto, space for walker frame, fixture $[4,5]$ bathroom tiles, handrail, alarm bell, ventilation, light and other related facilities $[6,7,8]$. Good toilet design can improves the quality of life of the elderly [4]. Therefore, in order to achieve good health of the elderly, to increase safety for the elderly to use the bathrooms, to reduce injuries and deaths of the elderly, the researchers conducted a study of health risks and safety assessments of the bathrooms for the elderly to use as proper guidelines and suggest effective improvements.

\section{METHOD}

\subsection{Participants}

The study received 278 respondents and investigated 278 elderly's bathrooms in Pa Phayom Sub-District, Phatthalung Province, Southern Thailand. The surveys were distributed, interviewed and assessed from 
February to April 2021. A cross-sectional survey was conducted among all the elderly (278 respondents).

\subsection{Data Collection}

A structured questionnaire consisted of questions divided into 3 parts: 1) personal data, 2) problem conditions in the bathroom use in the elderly's homes and 3) assessment of the elderly's bathrooms that were adapted from the standard of health accessibility safety (HAS), Department of Health, the Ministry of Public Health. The structured questionnaire had single choice, multiple choices and weight ranking. The questions on problem conditions in the bathroom use in the elderly's homes consisted of 12 items and assessment questions on bathroom safety in their homes consisted of 21 items. The questions were validated in content validity index (CVI). It is one of the quantifiable approaches to verify the content validity of a questionnaire. It permits experts to individually review and assess the relevancy of each item in a question by 3 experts. The CVI result was 0.82 , which indicated that the questionnaire is reliable.

The participants were purposively selected according to the inclusion criteria: the elderly aged more 60 years who speak Thai and gave their consent to this study. The exclusion criteria for the participants were the temporary living in $\mathrm{Pa}$ Phayom sub-district, Phattalung province. The research ethics committee of Thaksin University approved this study (COA No. TSU 2021-045, REC No. 0030). Before the participation, the participants received oral and written information about the study. Collecting data including their consents were obtained from all the participants.

\subsection{Data Analysis}

Data analysis was descriptive analysis for all parts of questionnaires. These data were performed by frequency, percentage $(\%)$, mean $(\overline{\mathrm{x}})$ and standard deviation (S.D.) table. Statistical tests were conducted using SPSS V24. Additionally, the problem conditions in the elderly's household bathroom use were analyzed based on the scores and each item was rated on a 5-point Likert scale (very low $=1$, low $=2$, moderate $=3$, high $=4$, very high $=5$ ). The mean scale of the problem conditions was interpreted on a 5-point Likert scale (no problem $=1.00-1.80$, acceptable $=1.80-2.61$, moderate $=2.62-3.42$, should improve $=3.43-4.23$, unacceptable $=4.24-5.00)$ and the assessments of their household bathrooms were analyzed based on the scores and each item was rated on a 3 -point Likert scale (pass $=1$, not pass/ be no $=0$ ). The mean scale of the bathroom safety was interpreted on a 5-point Likert scale (Unacceptable $=0-0.20$, Poor $=0.21-0.40$, Acceptable $=0.41-0.60$, Good $=0.61-0.80$, Excellent $=0.80-1.00)$.

\section{RESULTS}

\subsection{Personal Data Among the Elderly}

The main characteristics of the elderly in Table 1 showed the mean values of gender, age, status, family types, family members, number of the elderly at home and accidents of the elderly. Besides, risky areas to accident in the bathrooms and types of the accidents in the bathrooms, symptoms while using in the bathrooms, manners of bathroom use and cleaning frequency of the bathrooms were shown in Figure 1.

Table 1. Personal Data

\begin{tabular}{|c|c|}
\hline Personal data $(\mathrm{n}=278)$ & Frequency $(\%)$ \\
\hline Gender; Female & $191(68.71)$ \\
\hline $\begin{array}{l}\text { Age; between } 66 \text { to } 70 \text { years old } \\
\text { (average } 71.47 \pm 7.94 \text { yrs.) }\end{array}$ & $72(25.90)$ \\
\hline Status; Marital status & $184(66.19)$ \\
\hline Family types; Nuclear family & $145(52.16)$ \\
\hline $\begin{array}{l}\text { Family member; } 2-3 \text { family members } \\
\text { (average } 3.20 \pm 1.75 \text { members/family) }\end{array}$ & $135(48.56)$ \\
\hline $\begin{array}{l}\text { Number of the elderly at home }(\geq 60) ; 2-3 \\
\text { people }\end{array}$ & $161(59.71)$ \\
\hline $\begin{array}{l}\text { Accidents of the elderly have experienced } \\
\text { were 'yes' answers (average } 1.76 \pm 0.66 \\
\text { times/yr.) }\end{array}$ & $42(15.11)$ \\
\hline
\end{tabular}

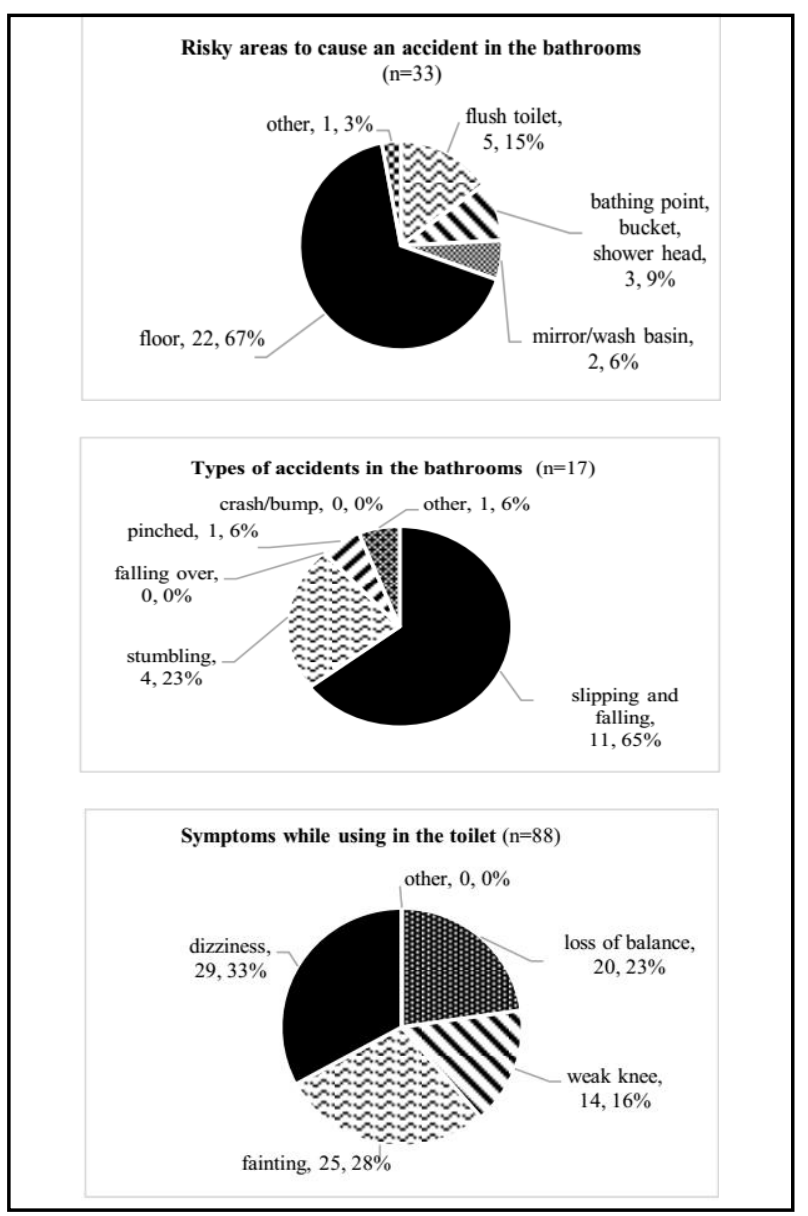

Figure 1 Health risks and safety data 


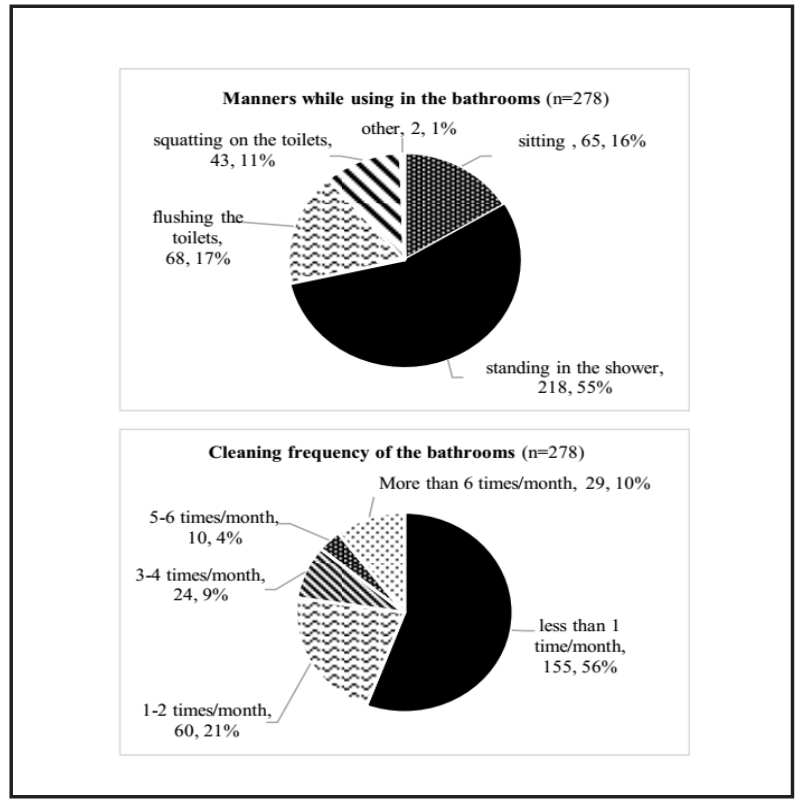

Figure 2 Health risks and safety data (Con't)

\subsection{Problem Conditions in the Elderly's Household Bathroom Use}

The overall level of the problem conditions in their household bathroom use was acceptable $(1.84 \pm 1.03)$ shown in Table 2.

Table 2. Problem conditions in their bathroom use

\begin{tabular}{|l|l|}
\hline \multicolumn{1}{|c|}{ Items } & $(\square \pm$ S.D.; Level $)$ \\
\hline $\begin{array}{l}\text { 1. Selection of sanitary ware and } \\
\text { inappropriate facilities such as the } \\
\text { toilet }\end{array}$ & $2.00 \pm 1.09 ; \mathrm{A}$ \\
\hline $\begin{array}{l}\text { 2. Improper installation of sanitary ware } \\
\text { such as location/installation distance }\end{array}$ & $1.93 \pm 0.96 ; \mathrm{A}$ \\
\hline $\begin{array}{l}\text { 3. Defective sanitary ware including } \\
\text { deteriorated/cracked, broken, cracked, } \\
\text { loose }\end{array}$ & $1.78 \pm 0.99 ; \mathrm{N}$ \\
\hline $\begin{array}{l}\text { 4. Accidents/possible injuries in the } \\
\text { bathrooms }\end{array}$ & $1.94 \pm 1.05 ; \mathrm{A}$ \\
\hline $\begin{array}{l}\text { 5. Cleanliness such as moss, water, mold, } \\
\text { accumulated stains }\end{array}$ & $1.99 \pm 1.07 ; \mathrm{A}$ \\
\hline $\begin{array}{l}\text { 6. Bad smell/air is not well ventilated or } \\
\text { poorly ventilated }\end{array}$ & $1.81 \pm 1.04 ; \mathrm{A}$ \\
\hline $\begin{array}{l}\text { 7. Insufficient lighting including } \\
\text { dim/blurry vision }\end{array}$ & $1.90 \pm 1.16 ; \mathrm{A}$ \\
\hline $\begin{array}{l}\text { 8. Poor drainage such as stagnant } \\
\text { water/sewer clogged }\end{array}$ & $1.75 \pm 1.01 ; \mathrm{N}$ \\
\hline $\begin{array}{l}\text { 9. The bathroom layout is cluttered with } \\
\text { obstacles, narrow spaces }\end{array}$ & $1.77 \pm 1.01 ; \mathrm{N}$ \\
\hline $\begin{array}{l}\text { 10. The floor or the bathroom wall is } \\
\text { broken, corroded, peeling off, damaged }\end{array}$ & $1.70 \pm 0.96 ; \mathrm{N}$ \\
\hline $\begin{array}{l}\text { 11. The bathroom door is damaged, } \\
\text { narrow, or low and the knob is } \\
\text { damaged. }\end{array}$ & $1.83 \pm 1.11 ; \mathrm{A}$ \\
\hline 12. Door edge/high threshold/level floor & $1.72 \pm 0.98 ; \mathrm{N}$ \\
\hline & $1.84 \pm 1.03 ; \mathrm{A}$ \\
\hline
\end{tabular}

Remark: no problem (N), acceptable (A), moderate (M), should improve (SI), unacceptable (U)

\subsection{Assessment of the Elderly's Bathrooms}

The overall health risk and safety level of the elderly's toilet were acceptable $(0.52 \pm 0.41)$ shown in Figure 2.

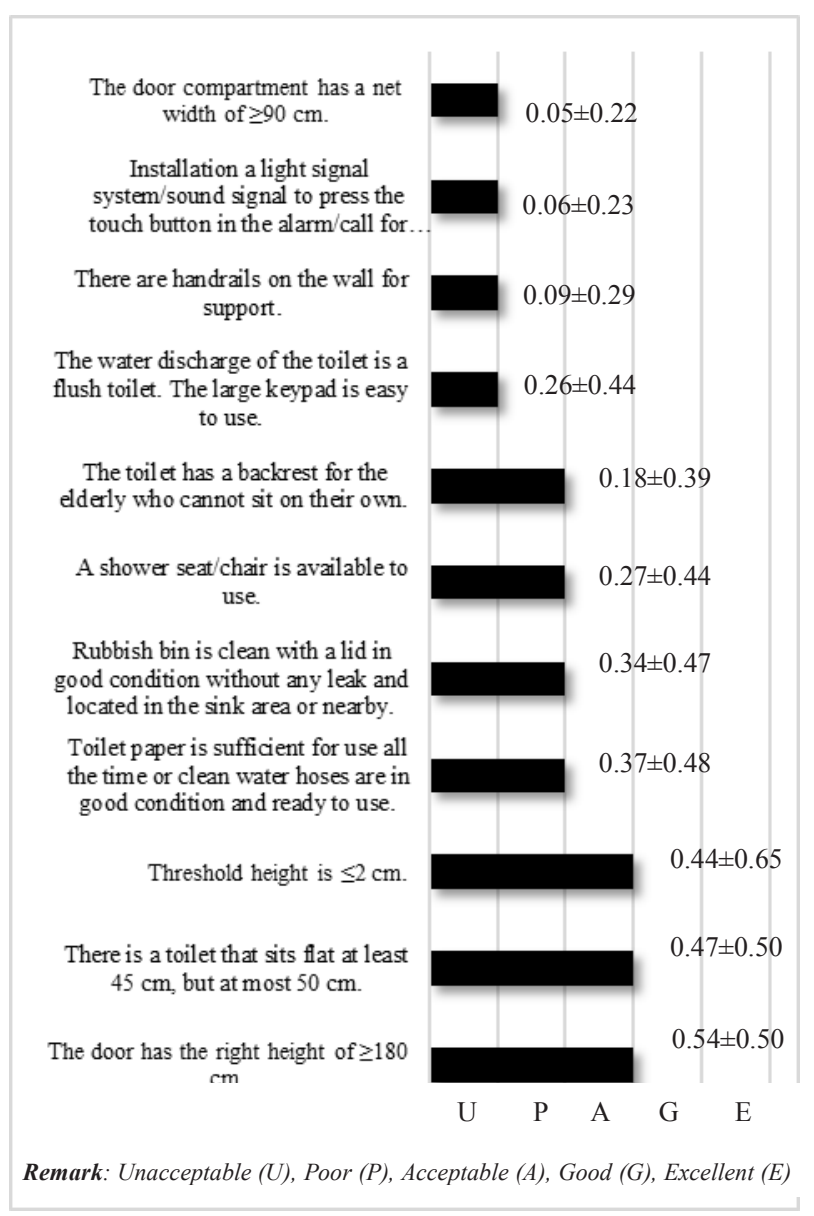

Figure 3 Assessment of the elderly's bathrooms

The values of the elderly's bathroom facilities were higher than the standard values. For instance, the door edge threshold height $\leqslant 2 \mathrm{~cm}$. was average $8.00 \pm 2.44$ $\mathrm{cm}$., Net width of $\geqslant 90 \mathrm{~cm}$. was average $74.85 \pm 7.97$ $\mathrm{cm}$. and door height $\geqslant 180 \mathrm{~cm}$. was average $178.73 \pm$ $10.18 \mathrm{~cm}$. as well.

\section{DISCUSSION}

The results showed that the family type of most of the elderly was nuclear family. The elderly live in a household with 2-3 family members. From the interviews, the family members who are of working age need to work in other provinces. So, the elderly have to take care of themselves. In addition, the study also found that the elderly have experienced accidents on average $1.76 \pm 0.66$ times/yr. Furthermore, cleaning the bathrooms less than 1 time a month can cause an 
accident there because the bathrooms are full of stain and fat causing slip and fall during their bathroom use. If the helpers or the authorities ignore to take a good care of the elderly, risky bathroom use can possibly harm their health or reduce safety. From the previous studies, the elderly are more prone to accidents. There was the situation of accidents in the elderly and self-care to prevent accidents among the elderly. The elderly living in nuclear families have to take care of themselves to prevent accidents by themselves through safety measures such as setting up a healthy environment inside and outside their homes [9].

According to the study, it was found that the majority of the elderly experienced dizziness when they used the bathrooms due to prolonged standing, bathing which is prone to breathing [3]. They have more chances to fall on the floor. These results were consistent with the previous study that found the danger of toilet or bathroom was falling $[4,10,11,12,13]$. The muscle strength in the upper and lower limbs of the elderly was degenerating, visual impairment, physical weakness, motion and sensory function decreases affected their balance ability [13, 14]. Therefore, the elderly need things to hold onto such as grip handles and handrails to provide them with a greater sense of safety. However, the study showed that there were no handrails on the wall for support or protection while using the bathrooms in case of falling and slipping. They still risk having harmful health effects. Additionally, the study reported that some of the elderly sit in the shower but they do not have shower seat or chair. They use it for washing hair or sitting during all toilet-related activities of undressing, washing, drying, dressing, brushing teeth and other activities in the bathrooms. Bathroom auxiliary facilities such as bath chairs, armrests, emergency call systems and other related items can effectively ensure the personal safety of the elderly.

The survey of the problem conditions of the elderly's bathrooms showed that the result was an acceptable level. However, the results on the assessments of the health risks and safety of their bathrooms conducted by the researchers were still poor and unacceptable levels because the elderly who answered the questionnaire still lacked understanding and were accustomed to the current conditions in their bathrooms. This caused the lack of improvements to reduce risky bathroom areas but to promote safer conditions. The opportunity of injury in the bathroom of elderly that mention supports the need for safety modifications such as grab bars and may indicate a need for assistance with bathing. The possible injuries in the bathroom among the elderly mentioned previously support the need for safety modifications such as grab bars and may indicate a need for assistance in bathing [13]. Additionally, participatory bathroom redesign for Indonesian elderly people offered two improvements for the bathroom design such as changing the seating position and adjusting the distance between the wall and the handrail used to assist in standing for elderly men [16]. Household bathing adaptations included the installations of the accessible shower and removal of physical barriers in the bathroom [17]. Such adaptations could improve the ability to manage their personal hygiene safely. Moreover, changing the tile surfaces against bathroom impacts for the elderly can alleviate their possible injuries due to falling down inside the bathroom. Changing the tile surfaces involves 3 factors: 1) a suitable type of bathroom tile surfaces for the elderly including bathroom features, 2) elderly manners while using the bathroom and 3) anti-slippery and antiimpact tile available in the market [18]. Furthermore, the guidelines to reduce and to prevent the possible falls inside the bathroom encompass the bathroom redesign divided into two parts: (1) the dry area consisting of the counter sink and toilet with hand rails (2) the wet area consisting of the sliding shower seat, hand rails and bathroom accessories. The redesign was performed to satisfy a high safety level [19].

Improving bathroom design and features is necessary but promoting the elderly physical health is crucial as well. A previous study showed that regular physical activity is safe for healthy and weak elderly people while the risks of falls, osteoporosis and muscular weakness could be minimized by regularly completing physical activities ranging from low intensity exercises such as walking to more vigorous sports and resistance exercises [20]. In addition, in order to prevent falls to avoid the possible injuries in Thai older people, there are developed programs which focus on fall risk assessment, fall education, exercise and cane use training, handing out a fall prevention handbook, home safety assessment, home visits, and giving reminders. Moreover, phone calls regarding fall prevention for the elderly were also effective, and helped to give them a feeling of being cared for and motivated behavioural changes [21].

\section{CONCLUSION}

The overall health risks and safety assessment of the elderly's bathrooms in $\mathrm{Pa}$ Phayom Sub-District, Phatthalung Province were acceptable. There were some specific items which could cause the health risks and reduce the safety of the elderly. The main health risks were insufficient toilet paper ready to use all the time, clean water hoses in poor conditions and not ready to use, no clean rubbish bin without a lid and water leaking. Such poor bathroom conditions affected the hygiene of elderly which needed constant care while bathroom facilities require proper maintenance. Main risks were no shower seat/chair and no backrest for the elderly who cannot sit on their own, water discharge of the toilet which is a flush toilet was not easy to use, no 
handrails on the wall for support and no light signal system or sound signal to call for help. These facilities need urgent improvements to protect the elderly and to prevent them from possible bathroom accidents. The authority can improve the bathrooms for the elderly to promote good conditions and safety effectively. Consequently, such improvements will increase their quality of life.

\section{ACKNOWLEDGMENTS}

The researcher would like to give special thanks to the Faculty of Health and Sports Science, Thaksin University for the research grant and support. In addition, the researcher would like to thank village health volunteers, sub-district administrative organization in $\mathrm{Pa}$ Phayom sub-district, the elderly and community innovator in $\mathrm{Pa}$ Phayom sub-district, Thaksin University for their collaborations in this study.

\section{REFERENCES}

[1] D. of O. P. of S. D. and H. Security, "Elderly Statistics," 2020. [Online]. Available: https://www.dop.go.th/th/know/side/1/1/335. [Accessed: 22-Feb-2020].

[2] K. Uchimoto, T. Yokoi, T. Yamashita, and H. Okamura, "Investigation of toilet activities in elderly patients with dementia from the viewpoint of motivation and self-awareness," Am. J. Alzheimers. Dis. Other Demen., vol. 28, no. 5, pp. 459-468, 2013.

[3] R. Han, D. Shao, and Y. X. Wang, "Design of senior family bathroom system based on demand theory," E3S Web Conf., vol. 179, pp. 1-7, 2020.

[4] Y. Kuboshima, J. McIntosh, and G. Thomas, "Bathroom Design for Assisted Showering That Improves the Quality of Life of the Elderly," J. Aging Soc. Chang., vol. 8, no. 3, pp. 69-89, 2018.

[5] E. C. King, V. M. Boscart, B. M. Weiss, T. Dutta, J. P. Callaghan, and G. R. Fernie, "Assisting Frail Seniors With Toileting in a Home Bathroom: Approaches Used by Home Care Providers," J. Appl. Gerontol., vol. 38, no. 5, pp. 717-749, 2019.

[6] A. Jaglarz, "Sustainable Development in the Concepts of Modern Bathrooms," Procedia Manuf., vol. 3, no. Ahfe, pp. 1638-1645, 2015.

[7] P. C. K. Chitpirom, "Problem Conditions of Toilets and Behavior of Toilet Users from Hirunruchi SubDistrict, Thon Buri District, Bangkok," Adv. Sci., pp. 54-68, 2017.

[8] A. P. and S. Fusakul, "Tile Surfaces forms against impact in Bathrooms for Elderly People," Arch J., pp. 46-56, 2011.
[9] K. N. R. Klungklang, "Accidental Situation and Self-Care for Prevention of Accident among Older People," J. Nurs. Heal. Care, vol. 37, no. 3, pp. 164-172, 2019.

[10] N. Edwards, J. Dulai, and A. Rahman, "A scoping review of epidemiological, ergonomic, and longitudinal cohort studies examining the links between stair and bathroom falls and the built environment," Int. J. Environ. Res. Public Health, vol. 16, no. 9, 2019.

[11] L. Y. Tsai et al., "Fall injuries and related factors of elderly patients at a medical center in taiwan," Int. J. Gerontol., vol. 8, no. 4, pp. 203-208, 2014.

[12] S. Vlavonou, T. M. Nguyen, and G. Touré, "Epidemiology of facial fractures in the elderly," JPRAS Open, vol. 16, pp. 84-92, 2018.

[13] J. A. Stevens, J. E. Mahoney, and H. Ehrenreich, "Circumstances and outcomes of falls among high risk community-dwelling older adults," Inj. Epidemiol., vol. 1, no. 1, pp. 1-9, 2014.

[14] M. Y. Jeon, M. O. Gu, and J. E. Yim, “Comparison of Walking, Muscle Strength, Balance, and Fear of Falling Between Repeated Fall Group, One-time Fall Group, and Nonfall Group of the Elderly Receiving Home Care Service," Asian Nurs. Res. (Korean. Soc. Nurs. Sci)., vol. 11, no. 4, pp. 290296, 2017.

[15] S. Saeed, M. Mahmoodabad, M. Zareipour, M. Askarishahi, A. Beigomi, and M. Z. Social, "Effect of the Living Environment on falls among the Elderly in Urmia the Creative Commons Attribution-NonCommercial 4.0 International License (CC BY-NC 4.0)," Maced. J. Med. Sci., vol. 6 , no. 11, p. 2233, 2018.

[16] S. G. Johanna Renny OCTAVIA, “3rd South East Asia Network of Ergonomics Society International Conference 2014," in Participatory Redesign of Bathrooms for Elderly People Living in Indonesian Retirement Homes, 2014.

[17] M. Golding-Day and P. Whitehead, "Bathing adaptations in the homes of older adults and their carers (BATH-OUT): A qualitative extended follow-up study with concurrent nested outcome assessments," BMJ Open, vol. 10, no. 11, pp. 1-9, 2020 .

[18] S. F. Araya Ekpranya, "Tile Surfaces forms against impact in Bathrooms for Elderly People," Arch J. Issue, vol. 12, pp. 15-56, 2011.

[19] Phetcharada Pacharee, "THE PREFABRICATION BATHROOM DESIGN FOR SLIP AND FALL ACCIDENTS PREVENTION IN THAI ELDERLY," Silpakorn University, 2014.

[20] J. S. McPhee, D. P. French, D. Jackson, J. Nazroo, N. Pendleton, and H. Degens, "Physical activity in 
older age: perspectives for healthy ageing and frailty," Biogerontology, vol. 17, no. 3, pp. 567580, 2016.

[21] N. Jitramontree, S. Chatchaisucha, T. Thaweeboon, B. Kutintara, and S. Intanasak, "Action Research Development of a Fall Prevention Program for Thai Community-dwelling Older Persons," Pacific Rim Int. J. Nurs. Res., vol. 19, no. 1, pp. 69-79, 2015. 